tions of the cubit, farther accuracy would be nearly useless, especially in view of the width and deficient symmetry of the dividing lines.

The zero point of the series is adjusted so as to fit the normal scale of equal spaces deduced from it, with equal errors + and on the series of palms.

\begin{tabular}{|c|c|c|c|c|c|c|}
\hline \multirow{2}{*}{\multicolumn{2}{|c|}{ End of rod }} & \multirow{2}{*}{$\cdots$} & \multirow{3}{*}{$\cdots$} & \multicolumn{3}{|c|}{ Pritish Inches. } \\
\hline & & & & & $\begin{array}{l}\text { bit Divisions. } \\
-026\end{array}$ & $\begin{array}{c}\text { Normal Scal } \\
.000\end{array}$ \\
\hline & & & & & 2.952 & $295^{6}$ \\
\hline & & & & & 5 . & $5.9 \times 3$ \\
\hline & & & & & $8 \cdot 873$ & 8.869 \\
\hline & & & & & II 820 & 11826 \\
\hline & & & & & 14.779 & 14785 \\
\hline Palms & $\ldots$ & . & & 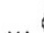 & I $7 \cdot 735$ & 17739 \\
\hline & & $\cdots$ & $\cdots$ & $\cdots$ & 20.702 & $20 \cdot 695$ \\
\hline & & & & & 23.665 & 23.652 \\
\hline & & & & & 26.605 & 26.608 \\
\hline & & & & & $\begin{array}{l}29502 \\
32.516\end{array}$ & $\begin{array}{l}29.505 \\
32.521\end{array}$ \\
\hline & & & & & $3548 \mathrm{r}$ & $35 \cdot 477$ \\
\hline Digi & $\ldots$ & $\ldots$ & $\cdots$ & $\ldots$ & $36 \cdot 195$ & 36.217 \\
\hline Condyle & $\ldots$ & $\ldots$ & .. & .. & 36.922 & 36.956 \\
\hline Digit & $\ldots$ & $\ldots$ & $\ldots$ & $\ldots$ & $37^{\circ} 694$ & 37.695 \\
\hline Palm & $\ldots$ & $\ldots$ & $\ldots$ & $\ldots$ & 38.417 & 38.434 \\
\hline Condyle & $\ldots$ & $\ldots$ & $\ldots$ & $\ldots$ & 39.910 & $39^{\circ} 912$ \\
\hline End of ro & & $\ldots$ & $\ldots$ & $\ldots$ & $4 \mathrm{I} \cdot 402$ & $41 \cdot 390$ \\
\hline
\end{tabular}

The average probable error of these determinations of each line (omitting the ends) is 0008 inch, so that it may be called I on the last place of figures here given.

The total length of the rod is $4 \mathrm{r}^{\circ} 428$ with a probable error of \pm -0025. Sir Gardner Wilkinson (and Queipo from him ?) states it as 4r 30 ; John Taylor, $4 \mathrm{I}^{\circ} 4 \mathrm{6}$; and Col. Sir Henry James, 4I.398. Thus the above determination falls between these three anthorities, and is in fact about reached by the pro. bable error of the mean of them.

Besides the total length of the rod, the divisions must be con. sidered as giving a value for the cubit. Leaving, therefore, for separate consideration the lesser subdivisions and ends, we wilt look cnly to the series of palms. As these were probably copied mechanically from arother standard, and were apparently not produced by stepping lengths on the rod, we should ascertain the mean value they give for a Normal scale, and their errors from it. This carefully computed from these palm divisions is $4 x^{\circ} 390$ for the cubit, or $2.95^{6}$ for each palm; and the average error of the palm divisions is $\mathrm{Oo} 7$ (the maximum error is or8), so the probable error of this value for the mean cubit is about 002 . This average error of $\mathrm{I}^{\frac{1}{* 2}}$ inch is rather large, but not worse than would probably be made at the present time in such work. By having a standard scale for comparison, hand dividing may be done on a still longer rod with a quarter of the error of this cubit, or even less; but as a mason's measure, this cubit is at least as accurate as modern examples.

The digit divisions are remarkable ; the two last fit the Normal scale as accurately as the palms, but in making the divisions $36^{\circ} 195$ and 36.922 , the scale has apparently slipped away from that end of the rod about 028 ; and thus these have an average - error of that amount. The ends appear to have been left rather long, perhaps to allow for wear, being 026 and oI I too long respectively, giving an average surplus of org. This may be intentional, or may result from being copied from a longer standard than the subdivided prototype, or may be merely' an error. In any case, the tolerable equality of the surplus at each end, seems to show that the subdividing was from another standard, and not by stepping successive distances, as the difference is only $\frac{7}{8000}$ of the total length.

In Queipo's Metrology the value of each palm of this example of the cubit is stated to the millionth of a metre, two places farther than really measured, as they are merely reduced from English inches and hundredths, with an occasional half-hundredth. These values are all about $\frac{1}{300}$ too short (their sum being $4 \mathrm{I}^{\circ} 3$, as Sir Gardner Wilkinson's statement), but otherwise they agree closely with the series given above; and their mean difference from it (when corrected for their general shortness) is 'OII, or but little more than the hundredth of an inch to which they were originally read.

If from the other eight or nine examples of the Karnak cubit the mean cubit was deduced from the subdivisions, and the internal errors of it thus obtained, we should have more knowledge of the accuracy of the earliest known civilisation, a datum of much interest from a scientific and historical point of view. A similar examination of the measures of classical and medirval times, including our ancient national standards of all kinds, would also give an idea of the accuracy which in various ages, and for various purposes, has been considered to be the utmost requisite; a meximum datum very different to that obtainable from other remains, which only show the amount of accuracy usually employed. As a chapter of the history of science, now so much considered, this subject should not be longer neglected.

Bromley, Kent

W. M. Flinders Petrie

\section{The Chemical Society}

TrIE article which appears in NATURE, vol. xiv. p. 125, on the Organisation of the Profession of Chemistry throws doubt on the expediency of effecting the proposed organisation through the instrumentality of a society which has solely occupied itself with the extension and diffusion of knowledge, viz., the Chemical Society. It farther proposes that as it would be a wide departure from the functions which the Cinemical Society has hitherto performed to undertake the appointment of a Board of Exa. miners, the Universities of Oxford, Cambridge, and London should be asked to co-operate in the matter, being already formed examining bodies, which would probably command and deserve greater confidence than a board nominated by a newly formed Institute, or even by the Chemical Society.

On these remarks I beg to offer the following comments :-

I. The Chemical Society never has promoted the acquisition of such knowledge and skill as are necessary for the discharge of such duties as a professional chemist is required to undertake.

2. If the Chemical Society has performed all other functions but this- the fact is no argument against it appointing a Board of Examiners, or of conferring some distinction on those who are capable of acting in the service of the public as chemists; indeed, if this may conduce to the "general advancement of chemical science," the Society, by not taking such steps, is scarcely fulfilling the duties for which it was originally founded, and by opposing any such scheme it may actually retard the progress of chemistry in this country.

3. The writer of the article is apparently unaware of the fact that it would be very difficult to make any examination answer the purpose of testing a man's skill and technical as well as scientific knowledge in a satisfactory manner. An organisation scheme has been designed by a few gentlemen in conjunction with myself, so as to obviate examination as far as possible, or, in other words, to extend the examination over a period of six years. Those of us who are teachers in medical schools, and particularly those who at times have had to take to "coaching" for a livelihood, see the defects of a system which entirely depends upon examination as a test of qualification. Certainly no University examination would have the confidence of professional chemists. There are many business details besides granting certificates of competency which an organisation of chemists would be obliged to undertake, as, for instance, imposing such observances on the members as would tend to suppress objectionable practices which are somewhat too common at the present time.

The Chemicat Neres for June 9 contains a sketch of an organisation scheme, and the conditions of admission for original members are there set forth. If the Chemical Society as a body agrees to accept such a scheme, by all means let it do so, but it does not appear clear whether the qualified Fellows of the Society could constitute a separate body, managing their own affairs, within the Society, without the interference of other Fellows not of the same class.

British chemists are now in request all over the world, Japan, India, China, Canada, and California, and some mark of distinction as "chemists" which those who go abroad might carry with them would be valuable to them and enhance the value of the science in this country. WALTER NOEL HARTLEY

Scientific Club, 7, Saville Row, W.

\section{Lectures on Meteorology}

IN these days of the rapid development of the standard sciences, and the multiplication of their offshoots into considerable sections nearly as big as their originators, it may not be inappropriate to represent the claims of meteorology for a separate existence apart from others. As geology and mineralogy have been developed out of the natural history of former times, so it may obviously be suggested that meteorology might be detached from natural philosophy with which it has been 